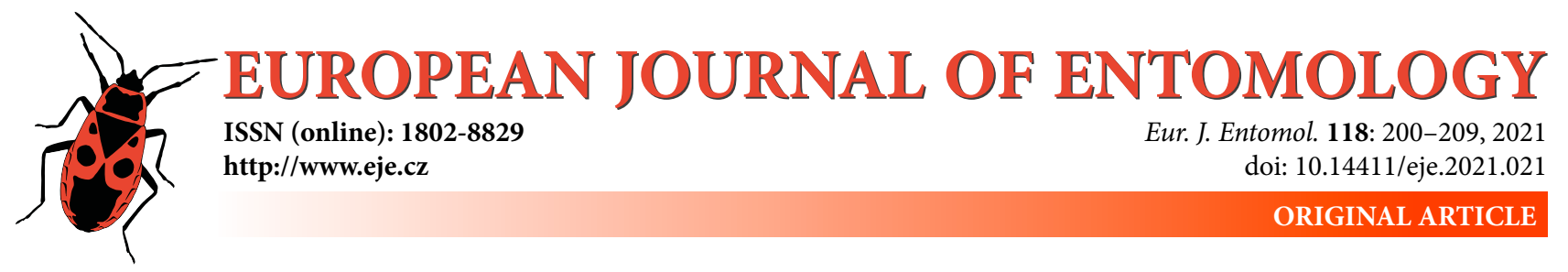

\title{
SOIL-INSECT toolbox: A new chamber for analysing the behaviour of herbivorous insects and tri-trophic interactions in soil
}

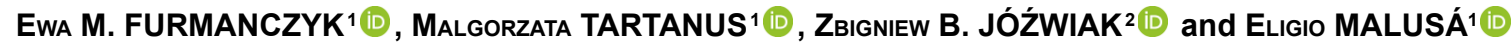 \\ ${ }^{1}$ Department of Plant Protection, The National Institute of Horticultural Research, Konstytucji 3 Maja 1/3, 96-100 Skierniewice, \\ Poland; e-mails: ewa.furmanczyk@inhort.pl, malgorzata.tartanus@inhort.pl, eligio.malusa@inhort.pl \\ ${ }^{2}$ Fruit and Vegetable Storage and Processing Department, The National Institute of Horticultural Research, Konstytucji 3 Maja \\ 1/3, 96-100 Skierniewice, Poland; e-mail: zbigniew.jozwiak@inhort.pl
}

Key words. Subterranean insects, behaviour, herbivory, tri-trophic interactions, biotest arena, carbon dioxide, Melolontha spp., volatile compounds

\begin{abstract}
A chamber, named SOIL-INSECT toolbox, was developed to analyse the effect of various factors on the behaviour of soil-dwelling insects. It is equipped with sensors that continuously monitor the concentration of $\mathrm{CO}_{2}$ in the different compartments of the chamber without disturbing the air balance in the soil. The chamber can be adapted to study different stimuli, including volatile compounds, both in the presence and absence of plants. The chamber was tested using the larvae of Melolontha spp., which confirmed its suitability for carrying out complex studies on insect-insect and insect-plant-microbiome interactions in a complex environment such as soil. The results of behavioural experiments using L3 larvae of Melolontha spp. in sterilized and natural soils revealed that the soil condition affected the behaviour of the larvae, likely due to its effect on the soil microbiome and physicochemical characteristics.
\end{abstract}

\section{INTRODUCTION}

The knowledge on belowground interactions between root-feeding insects, plants and the soil microbiome are still limited, in spite of the recent increase in studies on soil biodiversity (Shikano et al., 2017; Mercado-Blanco et al., 2018) and its relations with plant health (Zvereva \& Kozlov, 2012; Thompson et al., 2017). Interactions between soil-living herbivorous insects, plants and the soil environment form a complex network, but of great practical importance for agriculture and forestry. Indeed, the complexity of the soil environment (Ariño et al., 2008), the patchy distribution of soil pests (Schmidt \& Hurling, 2014) and the consequent difficulties in monitoring them, together with the limited number of active substances available for their control, have resulted in an increased risk of damage to crops. In this context, a better understanding of the mechanisms underlying plant-insect interactions and the behaviour of insects, as well as the influence of the soil microbiome, including that of the entomopathogenic species, could result in the development of new strategies for managing soil pests.

The difficulties encountered in behavioural studies of plant-insect interactions of soil-herbivores are related to not only the physical, chemical and biological characteristics of soil, but methodological. For instance, the host-plant localization process by soil-dwelling larvae is still unclear, even though the release of several secondary metabolites in the form of volatile organic compounds (VOCs) are known to act as repellents, attractants or signalling agents for soil herbivores (Loreto \& Schnitzler, 2010; Arimura et al., 2011; Bustos-Segura \& Foley, 2018; Paudel et al., 2019). In addition, VOCs from the soil microbiome (either plant-associated or free living) are known to influence the behaviour of herbivorous insects (Biere \& Bennett, 2013; Hassani et al., 2018; Grunseich et al., 2020). Nevertheless, a major plant metabolite attracting soil insects to plant roots is carbon dioxide (Johnson \& Gregory, 2006). On the other hand, plant roots are not the only belowground emitters of $\mathrm{CO}_{2}$, as soil living animals and microorganisms also release this compound as a result of respiration and decomposition of organic matter. The framework within which soil-insects and plants interact is further complicated by the characteristics of soil. Spreading of volatile compounds in the belowground soil-air complex differs significantly from their spread in atmospheric air as it depends on soil structure, pore space and overall soil properties (Rolston, 2005). Moreover, the techniques used to analyse volatile compounds in soil should be adapted to these specific conditions. As the gas exchange in soil is a passive processes (Stępniewski et al., 2011; Smith et al., 2018), the procedure for collecting volatile substances should be also based on static techniques, which only slightly disturb the natural 


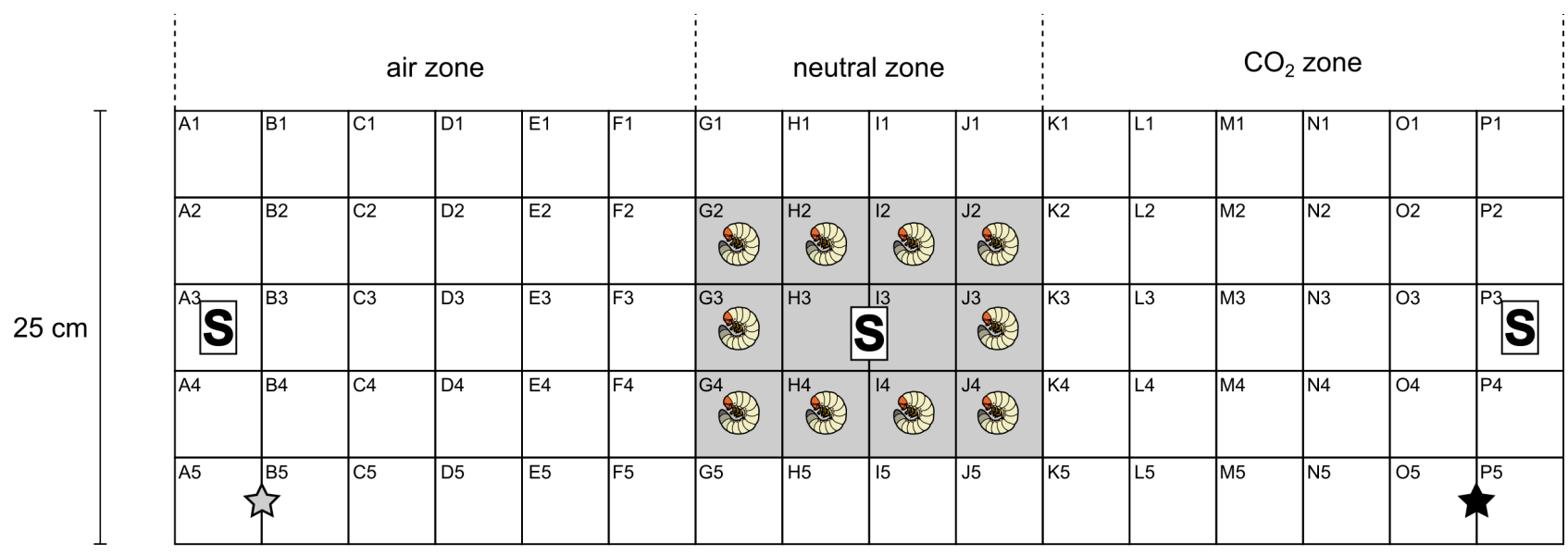

\section{$80 \mathrm{~cm}$}

Fig. 1. Schematic drawing of the observation chamber $(80 \mathrm{~cm} \times 25 \mathrm{~cm} \times 3 \mathrm{~cm})$ used in the experiments - side view of the chamber, which was divided into a grid made of 80 interspaces (each of $5 \mathrm{~cm} \times 5 \mathrm{~cm}$ size). The stars on A5 (grey) or P5 (black) indicate the air or CO, inlets, respectively; the grey rectangular area $(\mathrm{G}-\mathrm{J}: 2-4)$ in the middle of the chamber is the location of larvae at the beginning of each assay; the letter $\mathrm{S}$ indicates the position of three $\mathrm{CO}_{2}$ sensors.

environmental balance (McAlary et al., 2014a, b). Considering all these aspects, there is still the need for designing semi-natural systems (e.g. mesocosms), which will facilitate the study of the behaviour of soil-herbivores and the different factors that affect them.

Here we present a new kind of arena, named SOILINSECT toolbox, which could be used for studying the behaviour of soil-dwelling insects subjected to different conditions (e.g. VOCs, plants, microbiome, etc.). It was tested using the larvae of Melolontha spp., which are polyphagous pests causing severe damage to many horticultural and forestry plants (Dolci et al., 2006; Głowacka \& Sierpińska, 2012; Wagenhoff et al., 2014; Malusá et al., 2020; Pedrazzini et al., 2021). The validation of the system was carried out using a gradient of synthetic $\mathrm{CO}_{2}$ as attractant, assessing also the interference of the soil microbiome on the larvae activity.

\section{MATERIALS AND METHODS}

\section{Testing the chamber}

The distribution of the larvae was observed using a specially constructed chamber $(80 \mathrm{~cm}$ wide $\times 25 \mathrm{~cm}$ long $\times 3 \mathrm{~cm}$ deep $)$ made of transparent plexiglass ( $5 \mathrm{~mm}$ thick), which is illustrated in Fig. 1. The observation device was divided into 80 grids in 16 vertical and 5 horizontal rows (each grid is $5 \mathrm{~cm} \times 5 \mathrm{~cm}$ ). Inside the chamber, on the inner side of the front of the removable lid, three carbon dioxide sensors were attached (in the middle and at both ends of the lid) for monitoring the $\mathrm{CO}_{2}$ concentration during the assay (the chamber assembly is shown in Fig. S1). Each carbon dioxide sensor (CDM7160-C00, Figaro) was connected via a FT232 USB UART Board (mini) converter (Waveshare) to a laptop through a mini B-USB cable. The data were collected using ConcMeasure dedicated application (Figaro Engineering Inc., Japan) and stored in csv files. Each sensor monitored $\mathrm{CO}_{2}$ concentration at $2 \mathrm{~s}$ intervals during the whole assay $(5 \mathrm{~h})$. To minimize the contact of the electronic system of the sensor with soil they were each placed in a plastic string bag with a small hole enabling direct contact of the sensor with the soil (in addition the whole module was protected by a $1 \mathrm{~mm}$ mesh, which prevented soil entering the bag, Fig. S2).

\section{Chamber validation tests}

The chamber was first filled with peaty soil without insects to validate the chamber air tightness before it was used to evaluate the behaviour of Melolontha spp. larvae. Peaty soil was selected because it as an ideal substrate for such studies. $\mathrm{CO}_{2}$ concentration was monitored inside (in the vicinity of the $\mathrm{CO}_{2}$ inlet) and outside (just at the edge of the chamber, in the nearest position to the $\mathrm{CO}_{2}$ inlet) the chamber, as well as in the room where the experiment was carried out. The conditions in the assay were the same as in the behavioural experiments (i.e. for almost $5 \mathrm{~h}$ carbon

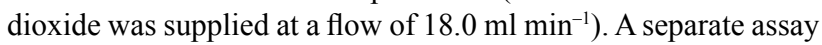
was carried out to evaluate the soil $\mathrm{CO}_{2}$ background inside the chamber in the absence of additional $\mathrm{CO}_{2}$.

\section{Behaviour of larvae of Melolontha spp.}

L3 larvae of Melolontha spp. were dug up at different locations in Poland and maintained individually in $200 \mathrm{ml}$ plastic containers filled with soil from the field from which they were collected and kept at $12-14^{\circ} \mathrm{C}$. They were fed pieces of carrot ad libitum. Two days $(48 \mathrm{~h})$ before the start of the experiments they were starved and kept at room temperature. Only individuals in good condition and active were used in the experiments and only once.

Before each experiment the chamber was filled with $4.3 \pm 0.1$ $\mathrm{kg}$ sterilized $\left(3 \mathrm{~h}\right.$ at $\left.150^{\circ} \mathrm{C}\right)$ or non-sterile peaty soil (sieved with $2 \mathrm{~mm}$ mesh) having approx. $10 \%$ moisture level, which is typical for the soil of the fields from which the larvae were collected. Ten L3 larvae of Melolontha spp. were placed in the middle of the chamber (columns G-J Fig. 1). The removable lid was fastened to the chamber using clamps; there was an EPDM rubber gasket at edge of the lid in contact with the other elements of the chamber, which ensured the whole system was air tight. The chamber was then covered with black plastic foil to assure complete darkness.

During each experiment the chamber was supplied with synthetic air at one end of the chamber (grey star Fig. 1), and $\mathrm{CO}_{2}$ (approx. 2.1\% in synthetic air) from the second end of the device (black star Fig. 1). The flow rate of the gases was controlled

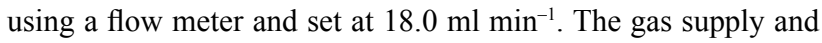
$\mathrm{CO}_{2}$ concentrations were continually monitored at the three points 


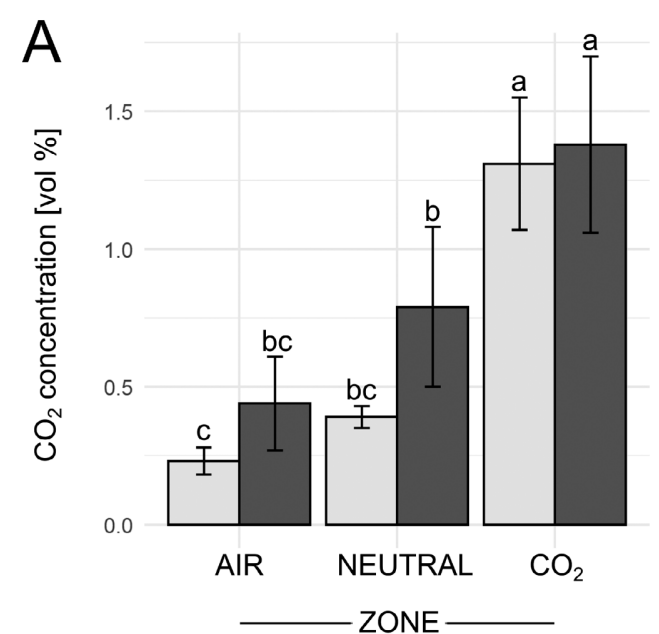

Nonsterile soil

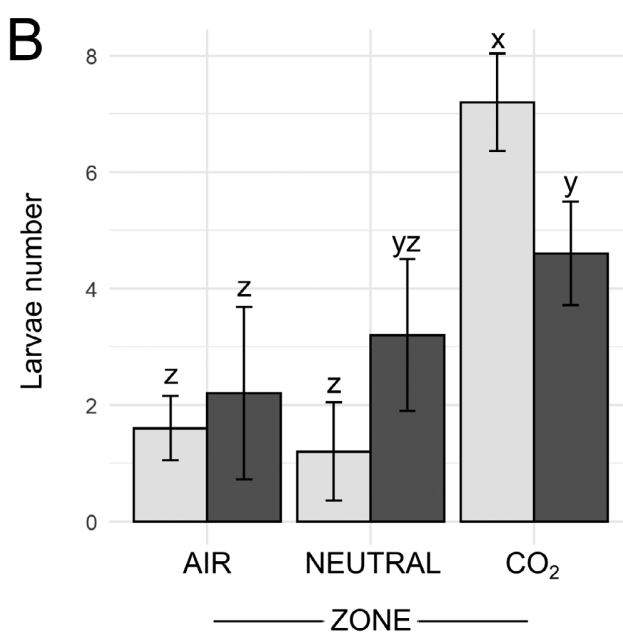

Sterile soil

Fig. 2. Carbon dioxide concentrations (Fig. 2A) and number of larvae (Fig. 2B) observed in the three compartments of the chamber with natural and sterilized soil. Means $\pm S D, n=5$. Different letters indicate significant differences between the compartments of the chamber ( $a b c$ for $\mathrm{CO}_{2}$ concentrations and $x y z$ for number of larvae) based on ANOVA and Tukey's post-hoc test at $p \leq 0.05$.

inside the chamber. The arena consisted of three zones: neutral, which was in the middle of the chamber, and air or $\mathrm{CO}_{2}$ zones, which were close to the respective gas inlet. At the end of experiment the position of each individual grub was recorded in terms of where it was in the grid square and zone of the chamber. There were 5 replicates of each experimental treatment, resulting in testing the response of 50 larvae of Melolontha spp. in both sterile and non-sterile soil to carbon dioxide. After each experiment the chamber was washed with detergent, rinsed with distilled water, dried and surface sterilized by exposure to UV light for $20 \mathrm{~min}-$ utes.

\section{Statistical analysis}

$\mathrm{CO}_{2}$ concentrations and numbers of larvae in the three zones (air, neutral and $\mathrm{CO}_{2}$ ) were compared statistically using $\mathrm{R}$ software version 3.5.0 (R Core Team, 2019). The Shapiro-Wilk test was used to verify whether data followed a normal distribution, and the Levene's test was used to verify the homogeneity of variances. The data were then analysed using ANOVA and differences between means tested using Tukey's test at $p \leq 0.05$ with HSD test function from the "agricolae" package of the R software.

\section{RESULTS}

The results of the validation tests on the chamber are summarized in Fig. S3. The preliminary tests confirmed the tightness of the system: no significant difference between $\mathrm{CO}_{2}$ concentrations near the chamber and in the room where it was housed and significantly higher $\mathrm{CO}_{2}$ concentrations in the chamber nearest the gas supply. The carbon dioxide concentration in the direct vicinity of the gas supply was also significantly higher than in the soil, indicating that this system could be used for determining the response of insects to $\mathrm{CO}_{2}$.

Carbon dioxide concentration in the $\mathrm{CO}_{2}$ compartment was significantly higher than in the neutral or air zones of the chamber in all experiments (Fig. 2A, statistical analysis of results in Table $\mathrm{S} 1$ ). In each experiment, $\mathrm{CO}_{2}$ concentrations measured in the neutral zone were slightly higher than in the air zone (Table S1), although not statistically significant. $\mathrm{CO}_{2}$ concentrations measured in the sterile soil were more variable than those recorded in nonsterile soil, with the coefficient of variation ranging from 23.5 to $37.4 \%$ for sterile soil and from 9.7 to 22.9 for nonsterile soil (Table $\mathrm{S} 1$ ).

L3 larvae of Melolontha spp. were attracted to the carbon dioxide source. In both of the soils tested the average number of larvae observed in the $\mathrm{CO}_{2}$ zone was always higher than in the two other compartments (Fig. 2B and Table $\mathrm{S} 1)$. The difference between number of larvae recorded in the $\mathrm{CO}_{2}$ and air zones was always statistically significant (Fig. 2B), indicating that L3 larvae were attracted 4-fold or 2-fold more by $\mathrm{CO}_{2}$ than by synthetic air in nonsterile and sterile soil, respectively. Moreover, the number of larvae recorded in the neutral compartment was always comparable (no significant differences) with the number recorded in the air zone, regardless of the type of soil used.

To visualize the strength of the response of L3 larvae of Melolontha spp. to carbon dioxide we analysed the spatial distribution of each individual inside the chamber (Fig. 3). The locations of larvae in the $\mathrm{CO}_{2}$ zone in sterile soil was more randomly distributed than in nonsterile soil, where the distribution was more uniform and consistently close to the $\mathrm{CO}_{2}$ inlet, indicating a straight movement of the larvae towards the inlet.

\section{DISCUSSION}

A chamber (SOIL-INSECT toolbox) for studying soildwelling insects was designed for analysing the effect of various factors on the behaviour of insects. The chamber is larger than a similar one used to study western corn rootworm larvae (Vemmer et al., 2016) and can be used to simultaneously monitor several individuals, thus enabling studies of tri-trophic (Shikano et al., 2017) and insect-insect interactions (Erwin et al., 2013), which are important for understanding the behaviour of soil-dwelling pests. The inclusion of passive $\mathrm{CO}_{2}$ sensors in the chamber for con- 


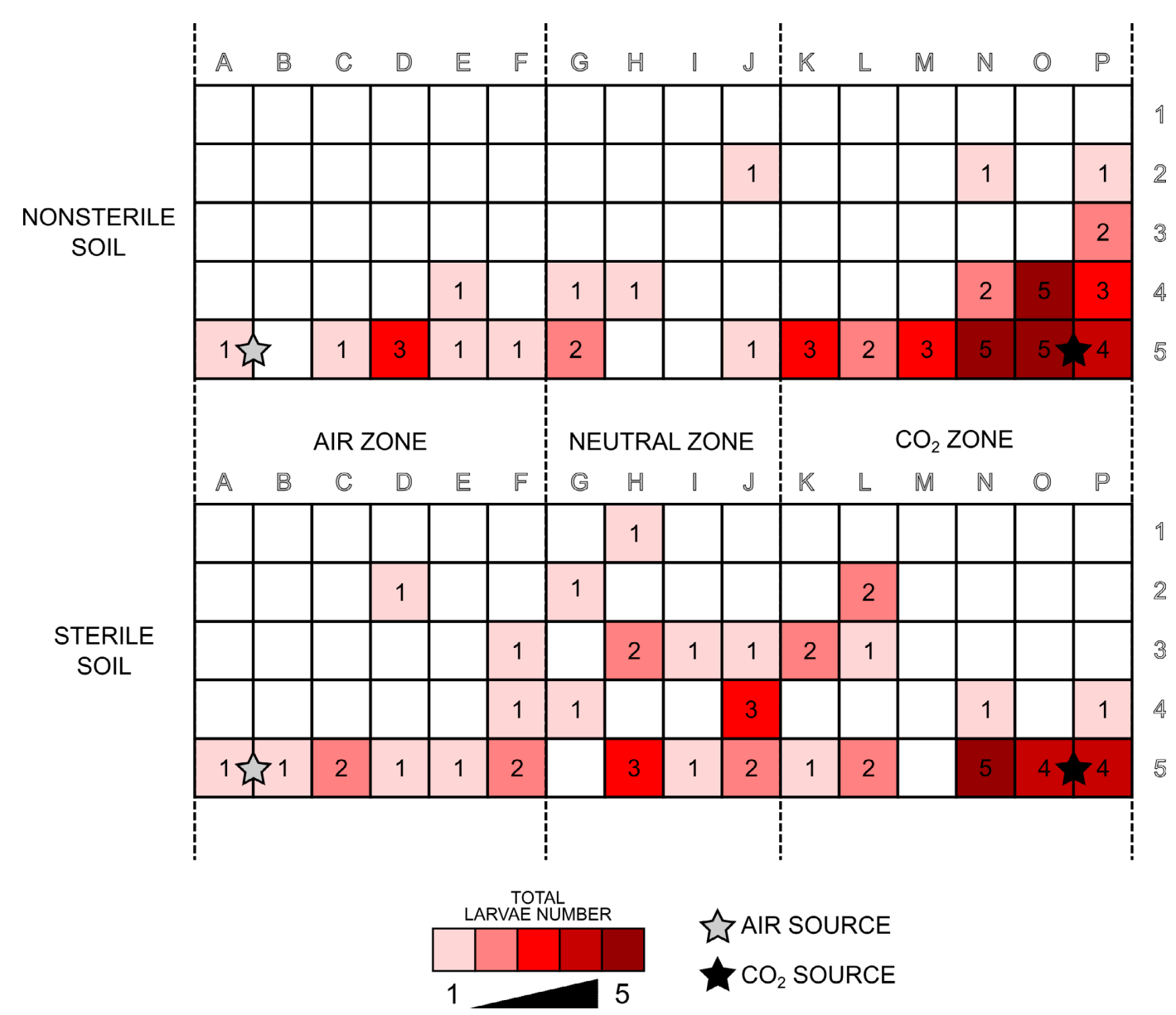

Fig. 3. Visual representation of the recorded positions of $L 3$ larvae of $M$. melolontha at the end of the experiments with both soil treatments. The number of larvae present in each square (as in Fig. 1) of the chamber is recorded. The stars indicate the synthetic air (grey) and $\mathrm{CO}_{2}$ (black) inlets.

tinuously monitoring carbon dioxide concentration without altering the soil gas flow dynamics, is a key feature of this system. The use of this kind of sensors makes this system better than those based on the analysis of collected soil-air samples, which sampling induces unnatural soilair circulation and disturbs the normal diffusion process of gases in soil (Rolston, 2005). The passive headspace collection of VOCs from the chamber could be also possible using polydimethylsiloxane sorbent in the form of silicone tubes (Kallenbach et al., 2015), which could be placed in the chamber instead of, or together with, the $\mathrm{CO}_{2}$ sensors.

The system could be considered as derived from the rhizobox system, designed for studying the root system architecture and rhizosphere properties (Sas Paszt \& Zurawicz, 2005; Neumann et al., 2009). The device presented, in addition to the above features, can be used to observe the movements of soil-dwelling insects and monitor soil carbon dioxide concentrations (and VOCs) at the same time, and could be used to sample the roots and rhizospheres of plants added to the system.

Olfactometers are regularly used to study the behaviour of aboveground insects (Turlings et al., 2004; Biasazin et al., 2018). However, monitoring soil-dwelling insects must overcome the impossibility of directly observing insects in soil. The recent development of highly sensitive sensors for acquiring the noise produced from the activity insects/ larvae provided an opportunity for studying larvae in soil (Görres \& Chesmore, 2019). Their specific noise patterns can be used to locate and even identify individuals of two species of Melolontha. However, preliminary studies carried out with the Soil-Insect toolbox revealed it was difficult to correlate the number of larvae to strength of the noise signal. Acoustic analysis could thus be a promising qualitative method for use in ecological studies. Another method explored in our laboratory was the use of microchips attached to insects (Karpelson et al., 2008). There are several kinds of microchips, which using radio frequency identification technology (RFID) can record the signal from individual insects only a few centimetres apart, like those used for goods tagging, which would make it possible to follow tagged insects even in soil (Moreau et al., 2011). However, the possible adverse effect of the microchip on insect movement or the difficulties of attaching it in a way that does not interfere with the insect's behaviour, prevented us from using this technology.

We tested the Soil-Insect toolbox for studying the movement of larvae of Melolontha spp. towards different stimuli in soil, using carbon dioxide as a simple attractant. L3 larvae of Melolontha spp. moved towards the source of carbon dioxide in the chamber. Plant roots release $\mathrm{CO}_{2}$ 
into the rhizosphere during respiration (Kuzyakov \& Larionova, 2005), which could act as a common cue for soil herbivores in locating plant roots. This was the case for species such as the giant rhinoceros beetle Trypoxylus dichotomus (Kojima, 2015) and the much smaller western corn rootworm (Bernklau et al., 2004). Studies on the role of $\mathrm{CO}_{2}$ in host plant localization by soil-dwelling insects were thoroughly reviewed by Johnson \& Gregory (2006). Experiments conducted by Reinecke et al. (2008) using an artificial substrate (vermiculite) confirmed this mechanism of attraction for larvae of M. melolontha. Interestingly, carbon dioxide readily diffuses in soil over relatively long distances (Hinsinger et al., 2005), therefore besides functioning as signalling compound for host-plant localization it could function as a carrier gas for other signalling substances such as VOCs.

In addition to validating the suitability of the new chamber for studying the behaviour of soil-dwelling insects, this study addressed whether the microbiome of soil could influence the orientation of larvae of Melolontha spp. in the soil. The attractiveness of $\mathrm{CO}_{2}$ depended on whether the soil was natural or sterilized. In the latter, less than half of the larvae in the arena moved towards the $\mathrm{CO}_{2}$ inlet, whereas about $50 \%$ or more grubs were attracted in case of non-sterilized natural soil. Natural soil is a complex multiphase, non-homogeneous substrate in terms of structure, porosity and nutrient content, highly colonized by microorganisms with a microbial biomass carbon representing $0.6-1.1 \%$ of soil organic carbon (Fierer et al., 2009). The soil microbiome contributes to the emission of VOCs in soil, with several compounds identical to those contained in root volatiles (Schenkel et al., 2015). Unsterilized soil might have provided a better habitat odour for the larvae in terms of background volatiles. The sterilization process used in the present study has surely affected the soil microbial content and, consequently, their capacity to emit VOCs, which could account for the differences observed between the two soils in terms of the orientation of the larvae to the $\mathrm{CO}_{2}$ source. In addition, the soil sterilization could have also influenced its physical structure and chemical characteristics, as was reported in different soils after $30 \mathrm{~min}$ of heating at $150^{\circ} \mathrm{C}$ (Badía \& Martí, 2003). Therefore, considering the complexity of the structure and texture of soil as well as the chemical characteristics of the microbial VOCs (lipophilic compounds with high vapor pressure and a low molecular weight) (Kanchiswamy et al., 2015; Schenkel et al., 2015), it could be hypothesized that the modifications induced by the sterilization process affected the $\mathrm{CO}_{2}$ flow and concentration in the soil and the production of microbial VOCs, which resulted in the differences between natural and sterilized soil.

The scattered pattern of the grubs in the arena might be due to the shape of the $\mathrm{CO}_{2}$ "cloud" in the soil. In the atmosphere, odour plumes depend on air movements and take the form of a "chemical trail" (Murlis et al., 1992). It can be speculated that similar trails might also be present in soil and changes in the physical characteristics of soil could have affected shape of the chemical trail and, thus, the differences observed in the orientation of larvae in the two soils. However, soil physical conditions, particularly moisture or liquid phase dispersion, temperature and gaseous diffusion, are the major factors influencing the transport of $\mathrm{CO}_{2}$ and air/odour movement in soil (Fang \& Moncrieff, 1999; Shen et al., 2013), which ultimately affects the behaviour of soil dwelling larvae. Therefore, further experiments are needed to investigate the effect of soil type, moisture and other physical-chemical properties on both gas/odour movement and the behaviour of larvae of Melolontha spp.

In conclusion, the SOIL-INSECT toolbox developed proved suitable for studying the behaviour of soil-dwelling L3 larvae of Melolontha spp. This chamber can be adapted for studying different stimuli, including volatile compounds, in the presence or absence of plants, without disturbing the air balance in the soil. Therefore, this chamber is suitable for carrying out complex studies on plant-insect interactions, including insect-insect and insect-plant-microbiome interactions in soil.

ACKNOWLEDGEMENTS. This work was funded by the project EXCALIBUR funded from the European Union's Horizon 2020 Research and Innovation Program under grant agreement No. 817946.

\section{REFERENCES}

Arimura G.-I., OzaWa R. \& Maffei M.E. 2011: Recent advances in plant early signaling in response to herbivory. - Int. J. Mol. Sci. 12: 3723-3739.

Ariño A.H., Belascó́in C. \& Jordana R. 2008: Optimal sampling for complexity in soil ecosystems. In Minai A.A. \& BarYam Y. (eds): Unifying Themes in Complex Systems IV. Springer, Berlin, Heidelberg, pp. 222-230.

BADÍA D. \& MARTí C. 2003: Plant ash and heat intensity effects on chemicaland physical properties of two contrasting soils. Arid Land Res. Manag. 17: 23-41.

Bernklau E.J., Fromm E.A. \& Bjostad L.B. 2004: Disruption of host location of western corn rootworm larvae (Coleoptera: Chrysomelidae) with carbon dioxide. - J. Econ. Entomol. 97: 330-339.

Biasazin T.D., Chernet H.T., Herrera S.L., Bengtsson M., Karlsson M.F., Lemmen-Lechelt J.K. \& DekKer T. 2018: Detection of volatile constituents from food lures by tephritid fruit flies. - Insects 9: 119, 14 pp.

Biere A. \& BenNetT A.E. 2013: Three-way interactions between plants, microbes and insects. - Funct. Ecol. 27: 567-573.

Bustos-Segura C. \& Foley W.J. 2018: Foliar terpene chemotypes and herbivory determine variation in plant volatile emissions. - J. Chem. Ecol. 44: 51-61.

Dolci P., Guglielmo F., Secchi F. \& Ozino O.I. 2006: Persistence and efficacy of Beauveria brongniartii strains applied as biocontrol agents against Melolontha melolontha in the valley of Aosta (northwest Italy). - J. Appl. Microbiol. 100: 1063-1072.

Erwin A.C., Geber M.A. \& Agrawal A.A. 2013: Specific impacts of two root herbivores and soil nutrients on plant performance and insect-insect interactions. - Oikos 122: 1746-1756.

FAng C. \& MoncriefF J.B. 1999: A model for soil $\mathrm{CO}_{2}$ production and transport 1: Model development. - Agric. For. Meteorol. 95: 225-236.

Fierer N., Strickland M.S., Liptzin D., Bradford M.A. \& Cleveland C.C. 2009: Global patterns in belowground communities. - Ecol. Lett. 12: 1238-1249. 
GŁowACKA B. \& SierPIŃSKA A. 2012: Control of adult cockchafers Melolontha spp. with Mospilan 20 SP. — Folia For. Pol. (A) 54: 109-115.

Görres C.-M. \& Chesmore D. 2019: Active sound production of scarab beetle larvae opens up new possibilities for speciesspecific pest monitoring in soils. - Sci. Rep. 9: 10115, 10 pp.

Grunseich J.M., Thompson M.N., Aguirre N.M. \& Helms A.M. 2020: The role of plant-associated microbes in mediating hostplant selection by insect herbivores. - Plants 9: 6, 23 pp.

Hassani M.A., Durán P. \& HacQuard S. 2018: Microbial interactions within the plant holobiont. - Microbiome 6: 58, $17 \mathrm{pp}$.

Hinsinger P., Gobran G.R., Gregory P.J. \& Wenzel W.W. 2005 Rhizosphere geometry and heterogeneity arising from root-mediated physical and chemical processes. - New Phytol. 168 : 293-303.

Johnson S.N. \& GREgoRy P.J. 2006: Chemically-mediated hostplant location and selection by root-feeding insects. - Physiol. Entomol. 31: 1-13.

Kallenbach M., Veit D., Eilers E. \& Schuman M. 2015: Application of silicone tubing for robust, simple, high-throughput, and time-resolved analysis of plant volatiles in field experiments. - BIO-Protoc. 5: e1391, 12 pp.

Kanchiswamy C.N., Malnoy M. \& Maffei M.E. 2015: Chemical diversity of microbial volatiles and their potential for plant growth and productivity. - Front. Plant Sci. 6: 151, 23 pp.

Karpelson M., Wood R. \& WeI G.-Y. 2008: A review of actuation and power electronics options for flapping-wing robotic insects. In: Proc. of the IEE International Conference on Robotics and Automation, Pasadena, CA, USA, May 19-23, 2008. Institute of Electrical and Electronics Engineers, pp. 779-786.

Колтма W. 2015: Attraction to carbon dioxide from feeding resources and conspecific neighbours in larvae of the rhinoceros beetle Trypoxylus dichotomus. — PLoS ONE 10: e0141733, $11 \mathrm{p}$.

KUZYAKOV Y. \& LARIONOVA A.A. 2005: Root and rhizomicrobial respiration: A review of approaches to estimate respiration by autotrophic and heterotrophic organisms in soil. - J. Plant Nutr. Soil Sci. 168: 503-520.

Loreto F. \& SCHNitzler J.-P. 2010: Abiotic stresses and induced BVOCs. - Spec. Issue Induc. Biog. Volatile Org. Compd. Plants 15: 154-166.

Malusá E., Tartanus M., Furmanczyk E.M. \& Łabanowska B.H. 2020: Holistic approach to control Melolontha spp. in organic strawberry plantations. - Org. Agric. 10: 13-22.

McAlary T., Groenevelt H., Nicholson P., Seethapathy S. Sacco P., Crump D., Tuday M., Hayes H., Schumacher B., JoHnson P. ET AL. 2014a: Quantitative passive soil vapor sampling for VOCs- part 3: field experiments. - Environ. Sci. Process Impacts 16: 501-510.

McAlary T., Wang X., Unger A., Groenevelt H. \& Górecki T. 2014b: Quantitative passive soil vapor sampling for VOCspart 1: theory. - Environ. Sci. Process Impacts 16: 482-490.

Mercado-Blanco J., Abrantes I., Barra Caracciolo A., Bevivino A., Ciancio A., Grenni P., Hrynkiewicz K., Kredics L. \& Proença D.N. 2018: Belowground Microbiota and the health of tree crops. - Front. Microbiol. 9: 1006, 27 pp.

Moreau M., Arrufat P., Latil G. \& Jeanson R. 2011: Use of radio-tagging to map spatial organization and social interactions in insects. - J. Exp. Biol. 214: 17-21.

Murlis J., Elkinton J.S. \& CARDÉ R.T. 1992: Odor plumes and how insects use them. - Annu. Rev. Entomol. 37: 505-532.

Neumann G., George T.S. \& Plassard C. 2009: Strategies and methods for studying the rhizosphere - the plant science toolbox. - Plant Soil 321: 431-456.
Paudel S., Lin P.-A., Foolad M.R., Ali J.G., Rajotte E.G. \& FelTON G.W. 2019: Induced plant defenses against herbivory in cultivated and wild tomato. - J. Chem. Ecol. 45: 693-707.

Pedrazzini C., Strasser H., Holderegger R., Widmer F. \& EnKERLI J. 2021: Development of a SNP-based tool for the identification and discrimination of Melolontha melolontha and Melolontha hippocastani. - Bull. Entomol. Res. [in press].

R Core Team 2019: $R$ : A Language and Environment for Statistical Computing. R Foundation for Statistical Computing, Vienna, Austria.

Reinecke A., Müller F. \& Hilker M. 2008: Attractiveness of $\mathrm{CO}_{2}$ released by root respiration fades on the background of root exudates. - Basic Appl. Ecol. 9: 568-576.

RoLston D.E. 2005: Aeration. In Hillel D. (ed.): Encyclopedia of Soils in the Environment. Elsevier, Oxford, pp. 17-21.

Sas Paszt L. \& Zurawicz E. 2005: Studies of the rhizosphere of strawberry plants at the research institute of pomology and floriculture in Skierniewice, Poland. - Int. J. Fruit Sci. 5: $115-126$.

Schenkel D., Lemfack M.C., Piechulla B. \& Splivallo R. 2015: A meta-analysis approach for assessing the diversity and specificity of belowground root and microbial volatiles. - Front. Plant Sci. 6: 107, 12 pp.

SCHMidT M. \& HuRLING R. 2014: A spatially-explicit count data regression for modeling the density of forest cockchafer (Melolontha hippocastani) larvae in the Hessian Ried (Germany). - For. Ecosyst. 1: 19, 16 pp.

Shen R., Pennell K.G. \& Suuberg E.M. 2013: Influence of soil moisture on soil gas vapor concentration for vapor intrusion. —Environ. Eng. Sci. 30: 628-637.

Shikano I., Rosa C., Tan C.-W. \& Felton G.W. 2017: Tritrophic interactions: Microbe-mediated plant effects on insect herbivores. - Annu. Rev. Phytopathol. 55: 313-331.

Smith K.A., Ball T., Conen F., Dobbie K.E., Massheder J. \& REY A. 2018: Exchange of greenhouse gases between soil and atmosphere: interactions of soil physical factors and biological processes. - Eur. J. Soil Sci. 69: 10-20.

StępNiEwSki W., StęPNIEWSKa Z. \& RożEj A. 2011: Gas Exchange in Soils. Soil Management: Building a Stable Base for Agriculture. John Wiley \& Sons, pp. 117-144.

Thompson L.R., Sanders J.G., McDonald D., Amir A., Ladau J., Locey K.J., Prill R.J., Tripathi A., Gibbons S.M., Ackermann G. ET AL. 2017: A communal catalogue reveals Earth's multiscale microbial diversity. - Nature 551: 457-463.

Turlings T.C.J., Davison A.C. \& TAMÒ C. 2004: A six-arm olfactometer permitting simultaneous observation of insect attraction and odour trapping. - Physiol. Entomol. 29: 45-55.

Vemmer M., Schumann M., Beitzen-Heineke W., French B.W., VidAl S. \& Patel A.V. 2016: Development of a $\mathrm{CO}_{2}$-releasing coformulation based on starch, Saccharomyces cerevisiae and Beauveria bassiana attractive towards western corn rootworm larvae. - Pest Manag. Sci. 72: 2136-2145.

Wagenhoff E., Blum R. \& Delb H. 2014: Spring phenology of cockchafers, Melolontha spp. (Coleoptera: Scarabaeidae), in forests of south-western Germany: Results of a 3-year survey on adult emergence, swarming flights, and oogenesis from 2009 to 2011. - J. For. Sci. 60: 154-165.

Zvereva E.L. \& Kozlov M.V. 2012: Sources of variation in plant responses to belowground insect herbivory: a meta-analysis. Oecologia 169: 441-452.

Received February 12, 2021; revised and accepted May 14, 2021 Published online July 7, 2021

Supplementary material follows (Table S1, Figs S1-S3). 
Table S1. Data recorded at the end of each replicate of the different treatments and results of the statistical analyses.

\begin{tabular}{|c|c|c|c|c|c|c|c|}
\hline \multirow{2}{*}{ Treatment } & \multirow{2}{*}{ Replicate } & \multicolumn{3}{|c|}{ Carbon dioxide concentration [\%] } & \multicolumn{3}{|c|}{ Number of larvae } \\
\hline & & Air zone & Neutral zone & $\mathrm{CO}_{2}$ zone & Air zone & Neutral zone & $\mathrm{CO}_{2}$ zone \\
\hline \multirow{5}{*}{ Nonsterile soil } & 1 & 0.3004 & 0.3836 & 1.0890 & 1 & 2 & 7 \\
\hline & 2 & 0.2495 & 0.3402 & 1.1008 & 2 & 2 & 6 \\
\hline & 3 & 0.2270 & 0.3886 & 1.3364 & 2 & 1 & 7 \\
\hline & 4 & 0.2050 & 0.4459 & 1.6823 & 1 & 1 & 8 \\
\hline & 5 & 0.1596 & 0.3978 & 1.3245 & 2 & 0 & 8 \\
\hline \multirow[t]{3}{*}{ Coeff. Variation \% } & & 22.86 & 9.66 & 18.44 & & & \\
\hline & 1 & 0.6521 & 1.0028 & 1.4691 & 2 & 2 & 6 \\
\hline & 2 & 0.5786 & 1.0912 & 1.8625 & 4 & 2 & 4 \\
\hline \multirow[t]{3}{*}{ Sterile soil } & 3 & 0.3489 & 0.7108 & 1.3259 & 3 & 3 & 4 \\
\hline & 4 & 0.3939 & 0.8105 & 1.2454 & 2 & 4 & 4 \\
\hline & 5 & 0.2500 & 0.3462 & 0.9824 & 0 & 5 & 5 \\
\hline Coeff. Variation \% & & 37.40 & 36.78 & 23.53 & & & \\
\hline \multicolumn{8}{|c|}{ ANOVA and post-hoc Tukey's test results } \\
\hline \multicolumn{8}{|c|}{ Carbon dioxide concentration in the three compartments $(p<0.001)$} \\
\hline \multirow{2}{*}{ Variant } & \multirow{2}{*}{ Compartment } & \multicolumn{3}{|c|}{ Nonsterile soil } & \multicolumn{3}{|c|}{ Sterile soil } \\
\hline & & Air zone & Neutral zone & $\mathrm{CO}_{2}$ zone & Air zone & Neutral zone & $\mathrm{CO}_{2}$ zone \\
\hline \multirow{3}{*}{ Nonsterile soil } & Air zone & - & 0.836 & 0.000 & 0.616 & 0.005 & 0.000 \\
\hline & Neutral zone & 0.836 & - & 0.000 & 0.999 & 0.069 & 0.000 \\
\hline & $\mathrm{CO}_{2}$ zone & 0.000 & 0.000 & - & 0.000 & 0.011 & 0.996 \\
\hline \multirow{3}{*}{ Sterile soil } & Air zone & 0.616 & 0.999 & 0.000 & - & 0.150 & 0.000 \\
\hline & Neutral zone & 0.005 & 0.069 & 0.011 & 0.150 & - & 0.003 \\
\hline & $\mathrm{CO}_{2}$ zone & 0.000 & 0.000 & 0.996 & 0.000 & 0.003 & - \\
\hline \multicolumn{8}{|c|}{ Average number of larvae in the three compartments $(p<0.001)$} \\
\hline \multirow{2}{*}{ Variant } & \multirow{2}{*}{ Compartment } & \multicolumn{3}{|c|}{ Nonsterile soil } & \multicolumn{3}{|c|}{ Sterile soil } \\
\hline & & Air zone & Neutral zone & $\mathrm{CO}_{2}$ zone & Air zone & Neutral zone & $\mathrm{CO}_{2}$ zone \\
\hline \multirow{3}{*}{ Nonsterile soil } & Air zone & - & 0.989 & 0.000 & 0.938 & 0.179 & 0.001 \\
\hline & Neutral zone & 0.989 & - & 0.000 & 0.649 & 0.053 & 0.000 \\
\hline & $\mathrm{CO}_{2}$ zone & 0.000 & 0.000 & - & 0.000 & 0.000 & 0.006 \\
\hline \multirow{3}{*}{ Sterile soil } & Air zone & 0.938 & 0.649 & 0.000 & - & 0.649 & 0.013 \\
\hline & Neutral zone & 0.179 & 0.053 & 0.000 & 0.649 & - & 0.000 \\
\hline & $\mathrm{CO}_{2}$ zone & 0.001 & 0.000 & 0.006 & 0.013 & 0.000 & - \\
\hline
\end{tabular}



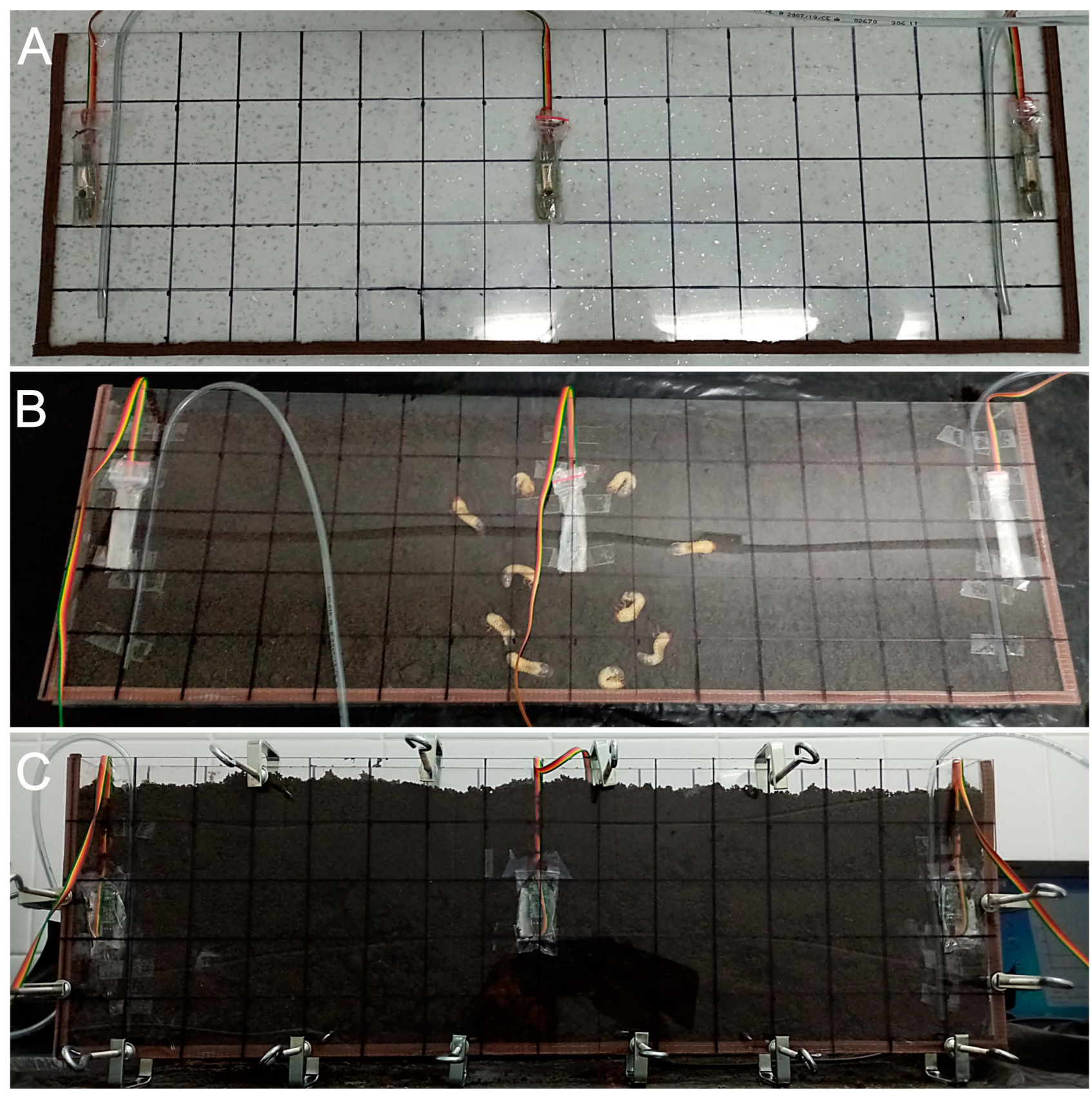

Fig. S1. Structure of the arena. A - removable lid with seal and attached sensors; B - chamber filled with soil and larvae of Melolontha spp. just before fastening the lid with clamps; $\mathrm{C}$ - chamber was kept in darkness during the experiment. 

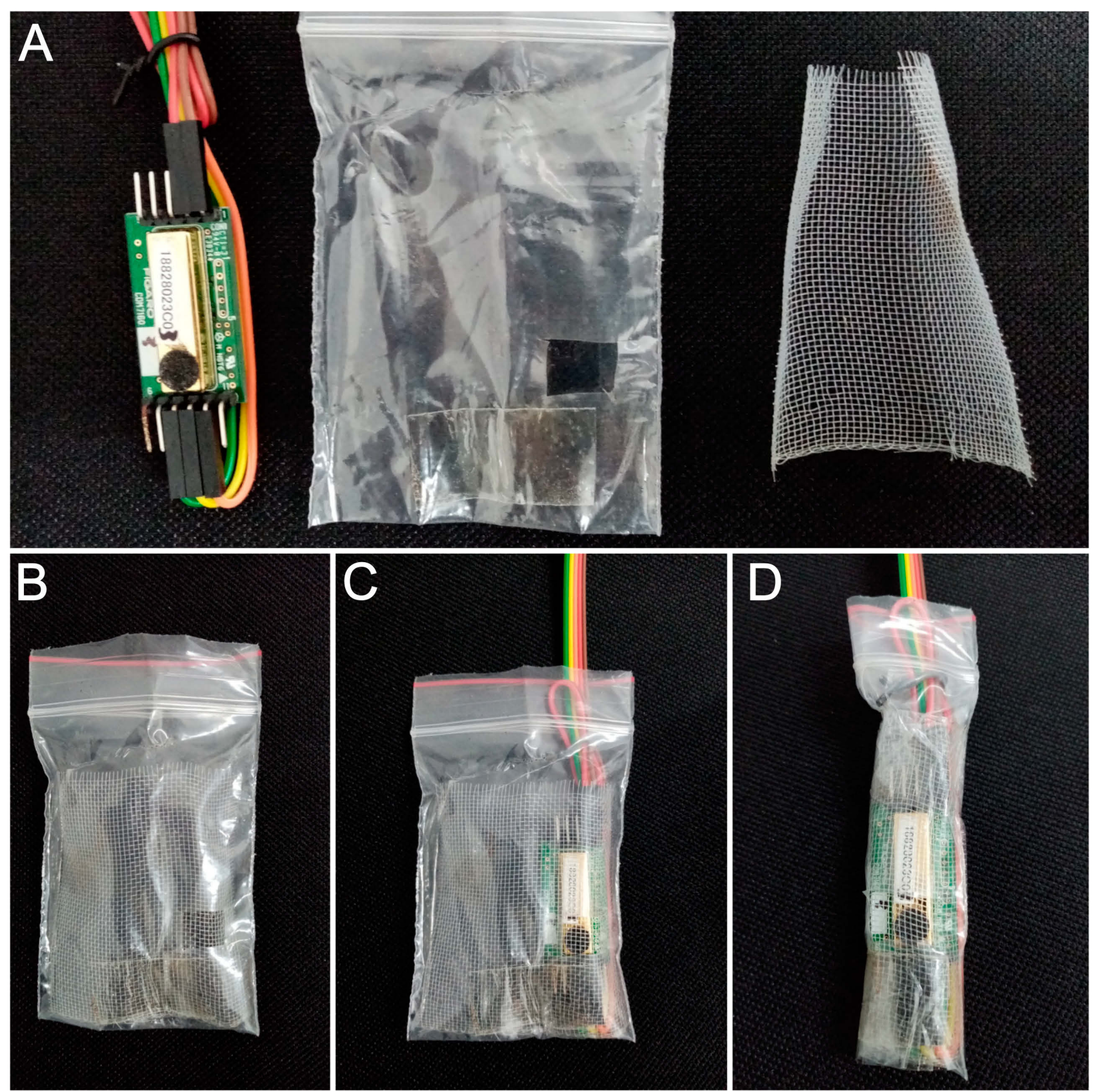

Fig. S2. Carbon dioxide sensor with cables connected to the computer, before placing it in a protective string bag lined with a $1 \mathrm{~mm}$ mesh (A). There is a hole in the mesh so that the sensor was in direct contact with soil (B) and the sensor was placed in bag (C) and tightly secured within the string bag (D). 


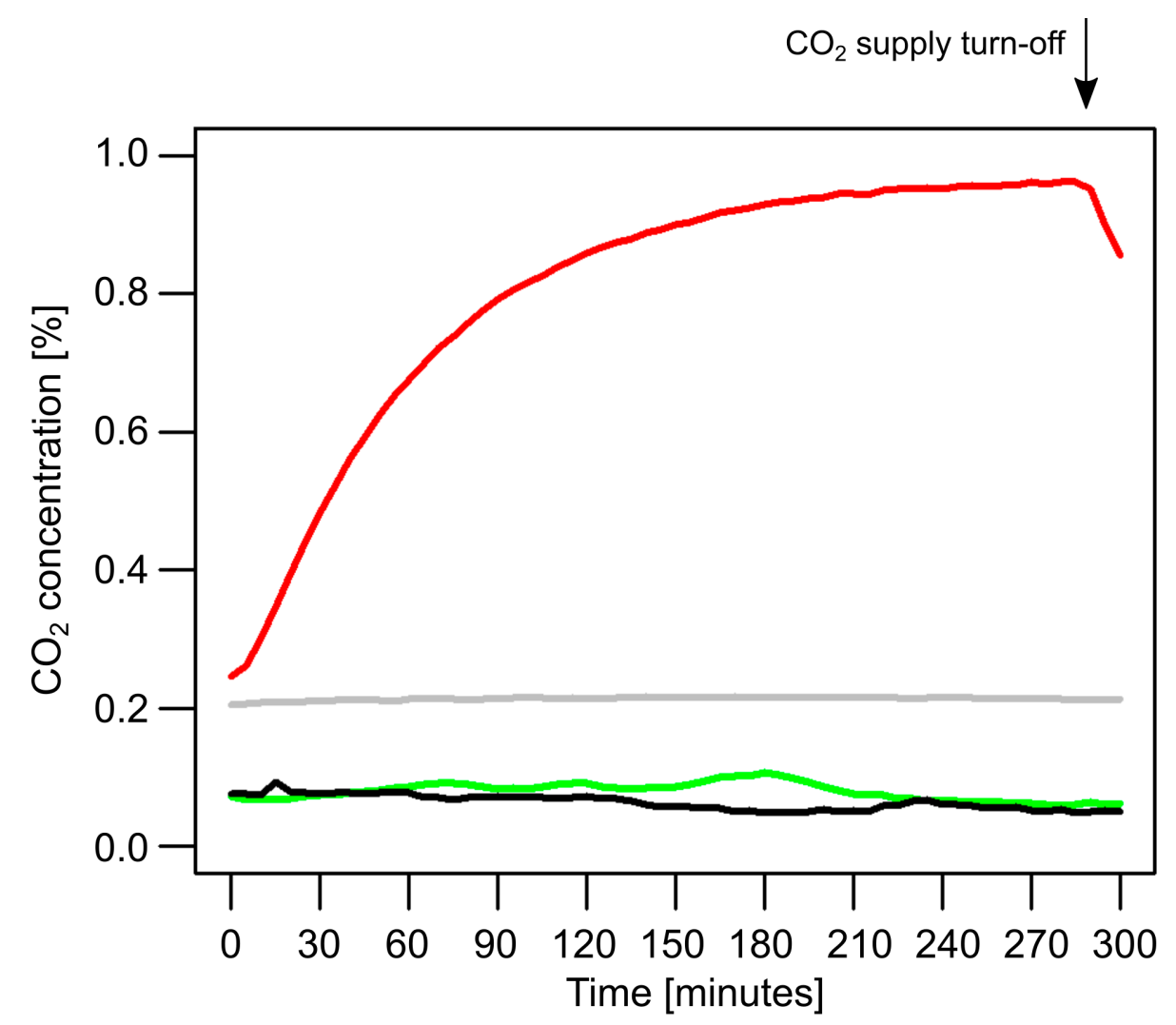

\begin{tabular}{|c|c|}
\hline \multicolumn{2}{|c|}{$\begin{array}{l}\text { Average } \mathrm{CO}_{2} \text { concentration during the validation experiment } \\
\text { (ANOVA with Tukey post-hoc test results, } p<0.05 \text { ) }\end{array}$} \\
\hline $0.626 \mathrm{a}$ & Ins \\
\hline $0.211 \mathrm{~b}$ & Outside $\mathrm{CO}_{2}$ concentration near the inlet \\
\hline $0.079 \mathrm{c}$ & Soil $\mathrm{CO}_{2}$ background without $\mathrm{CO} 2$ supply \\
\hline $0.059 \mathrm{c}$ & Room $\mathrm{CO}_{2}$ concentratrion \\
\hline
\end{tabular}

Fig. S3. Carbon dioxide concentrations in the various compartments during the validation tests and the statistical analysis of the results. 